\title{
Capacity-building for Youth Workers Through Community-based Partnerships
}

\author{
Ken Peake, Susan Gaffney, and Michael Surko
}

A Ithough positive youth development (PYD) is increasingly influential in the field of youth programming, core knowledge and competencies for youth workers continue to be defined. Youth serving agencies throughout the United States face serious obstacles in the creation of a stable and well-trained workforce, despite the presence of many talented and resourceful individuals who work with youth in the community. One strategy for organizational and staff development is through PYD-oriented, community-based partnerships designed to enhance youth worker knowledge and competence. Two different partnerships are described in this report. The first brought together experts in youth work, health, and trauma, and focused on improving youth worker response to psychologic trauma commonly experienced by urban youth. This partnership used an iterative reflective practice approach to describe best practices in youth work. The second partnership strategically taught evaluation skills to youth program consumers, AmeriCorps service members, and adult youth workers to advance youth-adult partnerships. These exemplars demonstrate that partnerships can drive systems for improving competencies in youth workers and the capacities of youth services.

KEY WORDS: adolescent, capacity building, community-based, logic model, partnership, professional development, reflective practice, trauma, youth development, youth-focused

Axiomatic to positive youth development (PYD) $)^{1-5}$ are the beliefs that "problem-free is not fully prepared" for the future, ${ }^{2\left(p^{20}\right)}$ and that effective prevention and remediation of problems require those who engage young people to provide opportunities for them to build personal and social assets that will prepare them for a healthy

J Public Health Management Practice, 2006, November(Suppl), S65-S71 (C) 2006 Lippincott Williams \& Wilkins, Inc. and productive adulthood. ${ }^{6}$ As described by Bernat and Resnick, and others in this supplement, PYD offers opportunities for researchers and practitioners to better understand the contribution of social and institutional factors to both adolescent health promotion and vulnerability. ${ }^{4}$

PYD also affirms that healthy development requires meaningful involvement of adolescents in their communities, and in the programs and institutions that serve them. ${ }^{7}$ However, community and consumer participation in traditionally bureaucratic medical institutions is not always welcomed, for both organization-cultural and practical reasons. ${ }^{8}$ Problemoriented public health funding and reimbursement for services tend to result in problem-focused approaches, with little incentive to adopt PYD practices. ${ }^{9}$ When PYD practices are adopted, they are sometimes misunderstood as an alternative to, rather than as an enhancement of, current models of public health or primary care. ${ }^{10}$ Thus, healthcare settings are not commonly considered as partners for youth serving agencies in PYD programming.

Youth serving agencies, themselves, may face obstacles in PYD programming because of the unmet need for a stable and well-trained workforce that has the knowledge and competence to address the myriad

We gratefully thank the following people for their major contributions to the work described in this article: Janet Kelley, MSW, Lissette Resto-Brooks, MSW, and Elizabeth Goodman, MSW, of Partnership for Afterschool Education; Angela Diaz, MD, MPH, of the Mount Sinai Adolescent Health Center; Robert Eleteza of SafeHorizon; and Marie Louis and Paul Josephson of Community Counseling and Mediation. We also thank Claude Chemtob, PhD, of Mount Sinai School of Medicine for his intellectual contributions and trauma expertise.

Corresponding author: Ken Peake, DSW, Mount Sinai Adolescent Health Center, 320 East 94th Str, New York, NY 10128 (e-mail: ken.peake@mssm.edu).

Ken Peake, DSW, is Chief Operating Officer and Assistant Director, Mount Sinai Adolescent Health Center, New York.

Susan Gaffney, MS, is Coordinator, Assets Coming Together for Youth Downstate Center for Excellence, Mount Sinai Adolescent Health Center, New York.

Michael Surko, PhD, is Assistant Professor of Pediatrics, Mount Sinai School of Medicine, New York. 
challenges facing both urban and rural youth. ${ }^{11-13}$ Staff shortages can lead to a focus on short-term, day-to-day operational problems, which in turn impede the development of far-sighted goals such as staff development. ${ }^{11}$ As a result, many youth worker jobs are part-time, which often create unstable staffing structures that make it more difficult for programs to deliver on the PYD principle that youth benefit from long-term relationships with concerned adults. Thus, Noonan ${ }^{11}$ has described working with youth in the United States as a developing, but still unrealized career track, in contrast to the UK, Irish, and Australian contexts in which youth work is a recognized and developing professional field. ${ }^{14,15}$ The youth worker field in this country faces a number of problems, including inadequate funding, an "elastic supply of low paid workers," and "negative return" on investment in advanced training (ie, the costs of continuing education exceed the salary benefits that can result). ${ }^{1(\mathrm{p} 5)}$ To become a recognized professional field, youth workers require (1) the identification of a core knowledge base, (2) a career "matrix that links roles, qualifications and compensation,"11(p2) (3) a system of training, (4) a training approval system, and (5) a registry of practitioners.

Camino and Zeldin identify the creation of partnerships for capacity building as a key strategy for organizational and staff competency development. ${ }^{12}$ While the two efforts described in this article do not address all of the challenges posed by Noonan, ${ }^{11}$ they serve, in the spirit of Camino and Zeldin's $\mathrm{s}^{12}$ recommendation, as practical exemplars of ways that core competencies can be defined and developed in youth service settings. This article presents two examples of partnerships involving a traditional adolescent health setting and other community organizations that were designed to enhance the capacity of community-based youth workers to engage in PYD. This increased capacity for PYD programming provides added value to community organizations in program marketing, participant recruitment and retention, staff recruitment and retention, as well as effectiveness studies. The first of these is not an example of PYD, per se, since youth involvement was not an essential element of its activities. Nonetheless, it is included in this supplement on PYD as a public health strategy because some organizations will find themselves needing this kind of capacity-building before attempting to institute full PYD programming.

The Mount Sinai Adolescent Health Center (AHC) is the nation's largest comprehensive adolescent-specific health center, with more than 40,000 visits annually. The AHC provides primary care and mental health services to urban teens and conducts research, medical education training, and technical assistance, all in- tended to promote the health of adolescents. ${ }^{4}$ A core component of AHC's mission is to influence adolescent health through the development of strategic partnerships within the youth serving and youth development communities. In New York City, where the capacity-building efforts were conducted, estimates of the number of children and youth involved in afterschool programs vary greatly, but may exceed a halfmillion. ${ }^{16}$ A number of efforts to strengthen YD programs have been initiated through groups such as The After-School Corporation and the Fund for the City of New York's Youth Development Institute. Two community-based partnerships collaborated with the AHC.

\section{Partnership for After School Education}

Partnership for After School Education (PASE) was founded in January 1993, when 60 New York City youth agency leaders and funders were convened to address serious issues in the overall quality and consistency of critical youth services in the city. Services lacked mechanisms to share effective program practices, to explore issues of concern to practitioners, and to develop resources. As a peer-led network that now includes more than 1,200 participating youth-serving agencies, PASE was designed to develop a strong service-system for youth through professional development of the field and to involve young people in public policy development. Formed with the explicit aim of developing the professional field in YD work, PASE was the locus for, and initiator of, the Partners in Healing (PIH) program.

\section{Partnership for Youth and Community Empowerment}

Partnership for Youth and Community Empowerment (PYCE) is a partnership of three youth-serving organizations in the North Crown Heights section of Brooklyn, New York. The PYCE was a local community development partnership, while the AHC was the center for excellence that provided it with technical assistance, in the statewide Assets Coming Together for Youth initiative described by Riser and colleagues elsewhere in this supplement. ${ }^{17}$ Thus, while PASE represented a vast network of more than 1,000 youth-serving agencies across New York City, the PYCE represented a much smaller group defined by a neighborhood. Each of these coalitions partnered with the AHC in ways that are illustrative for other public health entities interested 
in increasing the capacity of community-based groups, large or small, to engage in PYD programming.

\section{Methods}

\section{Partners in Healing}

The goal of Partners in Healing (PIH) was to build capacity among front-line youth workers by improving their ability to help young people living in urban settings address traumatic life experiences. Without attempting to turn youth workers into mental health professionals, the PIH aimed to build on their existing strengths to engage trauma-affected young people and, where appropriate, to help them build bridges to professional mental health services. AHC's role was the creation of a youth worker guidebook, developed concurrently during a yearlong series of trainings for youth workers. The youth workers represented 31 community-based organizations, and the training was conducted by PASE and SafeHorizon, a leading nonprofit, victim assistance, advocacy, and violence prevention organization.

To create a guidebook that was both well-informed and useful, the AHC recognized the need to identify existing best practices in the fields of PYD and youth work, and mental health and adolescent psychologic trauma, which would require expertise in youth work, program development, administration, youth communications, professional development, and social work. Many expert practitioners are not accustomed to distilling heuristics from their accumulated "practice wisdom" and articulating practice principles. ${ }^{18}$ Youth work training is generally hands-on, relying on having a supervisor directly involved in the service setting. While the PIH youth work experts actively train and supervise many youth workers every year, a significant challenge was to translate their practice wisdom into written principles and practical solutions. While one task was to tap their general expertise, a far more difficult task was to identify ways in which youth workers can respond appropriately to the common trauma-related issues of urban youth, without overstepping the limitations of their settings and roles.

To accomplish this, AHC engaged expert practitioners in the process of reflective inquiry.${ }^{19}$ This approach has been applied to understanding and iterating daily practice in human services, ${ }^{20-23}$ administration, ${ }^{24}$ and knowledge development. ${ }^{18,25}$ It assumes that (1) theorizing, thinking, and action are not distinct activities separated in time, but occur concurrently, and (2) effective practitioners solve practical problems by drawing on experience through an analogical, nonlinear pro- cess. Thus, the AHC's work involved drawing on experts' abilities to reflect on specific practice problems and strategies and solutions that emerge everyday in youth work.

To scope out the project, a PIH planning group (PIHPG) was convened, composed of regional experts in the fields of youth work, training, social work education, mental health, and trauma. In addition to PASE staff and AHC staff and faculty, the PIHPG included the Director of Youth Communications and a psychologist from the Mount Sinai Medical Center, two social workers from SafeHorizon, a professor of social work from New York University, and a social worker from the Mental Health Association of New York City. Planning sessions with the PIHPG were used by the AHC to conduct a state of the field assessment related to trauma and training challenges encountered in youth service settings, a gaps analysis, and a needs assessment. The PIHPG remained involved in steering the PIH project, but its initial work was to develop two key elements of the guidebook.

An outline for the guidebook content and for the organization was generated from the state of the field assessment. Content covered eight key areas: (1) recognizing the effects of trauma, (2) recovery from trauma, (3) building resiliency, (4) helping kids feel safe, (5) using groups to build resiliency, (6) promoting healthy approaches to grief and loss, (7) supporting the youth worker, and (8) linking with mental health providers. The PIHPG then developed a unified approach to content presentation simultaneous to the AHC surveying relevant literature and tools, contemporary resources, published guides, and training materials that reflected practice wisdom and research. Workgroups were formed to review content developed by AHC. PASE's extensive network of experts in PYD-related technical assistance, training, youth programming, and communications facilitated recruitment of workgroup members; the AHC's expertise was in working with traumatized youth and other professionals who engage youth around high-risk issues, such as human immunodeficiency virus/acquired immunodeficiency syndrome.

The final and most complex stage of content development entailed obtaining detailed, real-life exemplars of best practices. To accomplish this, four focus groups were formed of workgroup participants and their extended networks. Each was composed of experienced youth work trainers and supervisors, program developers, and trauma service experts. The groups focused on two subject areas each: (1) defining trauma and its impact/PYD strategies for strengthening resilience; (2) making the service setting a safe space/group strategies for fostering recovery; (3) grief, loss, and endings/agency preparedness; and 
(4) supporting staff/linking with mental health services. Each focus group meeting was taped and transcribed, and in-depth, follow-up interviews were conducted to clarify and expand content. The groups focused on questions such as the following:

- How should youth workers be trained to recognize manifestations of trauma?

- If a young person reveals a personal trauma during a group activity, how should the youth worker respond? What are the criteria for proper handling of disclosure?

- How are youth workers trained to know their own limits and not to exceed their professional skills, yet remain open and engaged so that the youth whom they serve can remain open and engaged?

- How should an inexperienced youth worker be trained to handle his or her own emotions and expressions?

- What youth service activities can contribute to addressing trauma? How can youth services ensure that youth who need professional help receive it?

- What are effective strategies for forming collaborations with mental health services?

- How might an agency respond to youth after a traumatic community event, such as a shooting? How do effective youth programs heal themselves after they have been affected by a traumatic event?

- What would the job description of a traumacompetent youth worker look like?

\section{Partnership for Youth and Community Empowerment}

Another method to build capacity with youth workers to prepare for YD programming in their agencies is illustrated by the out-of-school programs developed by the PYCE in North Crown Heights, Brooklyn. In this approach, the learning environment creates informal skills-development opportunities for program consumers, young adults, and adult staff members, and internal capacity-building is supplemented by formal training and technical assistance delivered by external experts.

\section{Internal capacity-building}

AmeriCorps members aged 18 to 22 years partnered with full-time, adult youth workers from social service agencies to establish out-of-school programs. The AmeriCorps members committed to a year of part-time public service in exchange for training and a small stipend, and were responsible for planning, implementing, and staffing the programs. Offerings included entrepreneurial silk-screening, drama and debate, sports tournaments, mock court, and conducting a large community survey of more than 5,000 youth each sum- mer. The programs were designed so that the program consumers, along with the AmeriCorps members who planned and ran the programs, gained experience that would be educational and relevant to workforce participation and later habits of civic engagement and service.

In this model, the distinction between youth program consumers and adult youth workers was intentionally blurred; the AmeriCorps members were given a set of opportunities and support as a means of promoting their own positive development, and in turn provided opportunities and support for children and younger teens. Thus, they were both the recipients and providers of YD interventions. This duality allowed both internal and external capacity-building to be focused on the AmeriCorps members, as well as on the full-time adult youth workers. Although both AmeriCorps members and adult agency staff provided youth work services, for the sake of clarity we will use the terms "program consumer," "AmeriCorps member," and "youth workers."

Capacity with AmeriCorps members was built and maintained by their participation in a 60 -hour orientation covering topics such as history of national service, recognizing and addressing child abuse, classroom management, team-building activities, play therapy techniques, and project and lesson planning. Each AmeriCorps member had to demonstrate mastery of the material before participating in the delivery of training. Youth workers also received targeted training intended for adult agency staff.

Added to the formal internal capacity-building for youth workers described above were informal means of enhancing preparedness for YD work within programs. For example, some individuals had prior experience in the program as consumers and/or AmeriCorps members. The multiple levels of participation, as program consumer, AmeriCorps member, and/or youth worker, reflect an intentionally designed progression of involvement for young people who wished to stay active in the programs over time. Within a program that serves approximately 250 young people annually, 7 consumers became AmeriCorps members, 10 AmeriCorps members became youth workers, and 2 former AmeriCorps members became program directors over a 4-year period. Program experience gained by young people as consumers helped prepare them to assume roles as full-time agency staff. In addition, the youth workers expressed openness to learning from AmeriCorps members, both through written feedback on program activities and through adopting new practices developed by the AmeriCorps members.

\section{External capacity-building}

AmeriCorps members and youth workers both received training and technical assistance from the AHC 
through its Assets Coming Together for Youth Center for Excellence, described in greater detail in the article by Riser and colleagues elsewhere in this supplement. Training sessions by AHC staff included more general topics, as well as those that were tailored to the specific needs of one youth program. For example, one training session focused on fundamental concepts of public health and survey design. Health concepts included defining a population by one or more characteristics (eg, geographic, health behaviors), types of community health (eg, physical \& mental health, civic responsibility, education, economic security, physical and social environment), and prevention strategies that can be used to reduce risk for negative health outcomes. Survey concepts addressed included fundamental principles of survey design and administration, as well as the types of survey questions used. AmeriCorps members then drafted surveys that focused on five public health topics and received technical assistance from AHC staff to refine and edit the surveys. Youth program consumers, with supervision from the AmeriCorps members, collected and analyzed the survey data and produced written reports, the results of which were presented to community leaders and at a city gang awareness conference. Youth workers reported that the training helped the AmeriCorps members develop broader concepts of community health and produce more rigorous (although still nonscientific) surveys.

Other examples of external capacity building involved training sessions for both AmeriCorps members and youth workers to prepare them to evaluate the programs that they ran. Training began with the concepts of developmental assets and positive developmental settings, and then covered components of a logic model and of a consumer satisfaction survey. ${ }^{26}$ In the first session, AmeriCorps members created logic models of the programs they ran. In the second session, they learned the principles of designing program participant surveys and created sample survey items that could assess consumer satisfaction and examine program elements identified in the logic models. AmeriCorps members demonstrated mastery of the concepts by drafting logic models of their programs, editing them with feedback from AHC staff, constructing a consumer satisfaction survey and key elements of their logic models (eg, are they reaching their target population, is the program space safe, clean, and attractive, do participants like the activities). Although this training was initially developed for the AmeriCorps members, youth workers requested it for themselves after they observed the AmeriCorps members produce and use logic models for their programs. Sometimes intimidating for adults with experience in program development, logic modeling was quickly grasped by AmeriCorps members who became fluent in using the framework. The program logic models guided the development of program participant surveys and the logic model terminology became a common language that was adopted by the adult staff.

\section{Results/Discussion}

\section{Partnership for After-school Education and Partners in Healing program}

Many mental health professionals who interact with young people are not aware of their adolescent clients' exposure to community violence, fail to ask about such exposure ${ }^{27}$ and fail to ask about the risk of exposure. ${ }^{28,29}$ Preliminary findings from the evaluation of PIH show that all of the 31 participating agencies reported that trauma is now part of their everyday focus. As a result, they are handling it more effectively and the youth they serve have improved access to mental health services. They reported an increased collaboration among youth workers to address the needs of traumatized youth, rather than removing them from program activities when they react with behavioral problems, as occurred previously. Overall, youth workers reported an increased acceptance of a role for mental health service providers and mental health discussions in the setting of a youth service program. In addition, PIH had significant unanticipated impacts, such as the establishment of, or improvement in, systems for tracking all youth across programs within each agency, including those with and without mental health needs.

The PIH initiative demonstrates that a broad-based partnership can bring tremendous and widely varying expertise at the community level to improve the performance of individual youth workers, program directors, and programs. As a result of collaborating with the AHC, the PIH partners came to recognize that they and health and human service sectors with which they had rarely, if ever, interacted were now identifying common goals. With capacity building as the primary objective, the focus on adults in community settings was a logical point of intervention. Thus, although YD was not an immediate goal of this project, increasing the knowledge and competence of staff and administrators in youth serving agencies is a necessary first step in preparing organizations to be ready for YD programming. The absence of youth representation in program development, and of a data-collection process on the youth impact at the agency level, indicates areas for improvement in future efforts that will move toward the ideal goals of PY articulated by Schulman elsewhere in this supplement. However, enhancing organizational readiness is often the first step in preparing for YD programming. 


\section{Partnership for Youth and Community Empowerment}

The PYCE initiative was characterized by the richness of the learning environment that emerged and the fact that youth program consumers, AmeriCorps members, and youth workers all learned from one another. A 2month follow-up by AHC staff demonstrated that some of the practices developed in the training were being used. For example, the logic model had been adopted, which the adult staff would have been unlikely to embrace in the absence of the strongly favorable reaction from the AmeriCorps members. In addition, both AmeriCorps members and youth workers had adopted the language of the logic model and logic modeling had become the primary method for program development. Evaluation and participant feedback had been incorporated into everyday practice and was now the norm.

\section{Conclusion}

Whereas the PIH initiative took a top-down approach with expert trainers working with adult staff only, the PYCE initiative employed a youth-adult partnership model characterized by youth and adults receiving training together and working collaboratively on program planning, program development, and program evaluation. While the latter example incorporated the PYD practice of involving young people directly in its implementation, the former initiative also has a significant implication for PYD. It demonstrated that PYD, which emphasizes a strengths-based approach in which youth are actively involved throughout program development, can benefit directly by having adults in youth service programs focus on the very real problems with which many youth struggle. While addressing social pathologies, the PIH initiative leveraged PYD principles by building on the capacity and strengths of youth workers and youth services. Although the two exemplars presented here are remarkably different in their scope and aims, together they demonstrate that partnerships can drive systems for improving competencies in youth workers and the capacities of youth services. Moreover, they each relied on the staff of an urban AHC, an entity often not considered as a partner in youth service sectors. These staff provided training and technical assistance to build capacity, demonstrating that healthcare service providers can have an important role in the public health practice of PYD.

\section{REFERENCES}

1. Lerner RM, Lerner JV, Alemerigi JB, et al. Positive youth development, participation in community youth development programs and community contributions of fifth-grade adolescents: findings from the first wave of the 4-H study of positive youth development. J Early Adolesc. 2005;25:1771.

2. Pittman K, Irby M, Ferber T. Unfinished business: further reflections on a decade of promoting youth development. In: Youth Development: Issues, Challenges and Directions. Philadelphia, Pa: Public/Private Ventures; 2000:17-64.

3. Pittman K. Balancing the equation: communities supporting youth, youth supporting communities. Community Youth Dev J. 2000;1:19-24.

4. Diaz A, Peake K, Surko M, Bhandarkar K. Including at risk adolescents in their own health and mental healthcare: a youth development perspective. Soc Work Ment Health. 2004; 3(1/2):103-120.

5. Lerner RM. Theoretical frames for understanding and enhancing adolescent development. Paper presented at: the National Academy of Sciences; September 8, 2005; Washington, DC.

6. Scales PC, Leffert N. Developmental Assets: A Synthesis of the Scientific Research on Adolescent Development. Minneapolis, Minn: Search Institute; 1999.

7. Hughes DM, Curnan SP. Community youth development: a framework for action. Community Youth Dev J. 2000;1. Available at: http://www.cydjournal.org/2000Winter/hughes. html. Accessed September 4, 2005.

8. Peake K, Brenner B, Rosenberg G. Community development and lay participation. In: Rehr H, Rosenberg G, Blumenfield S, eds. Creative Social Work Health Care. New York: Springer Publishing; 1998:103-115.

9. Diaz A. Positive youth development and adolescent health promotion: strengths, challenges \& issues to consider. Paper presented at: the National Academy of Sciences; September 8, 2005; Washington, DC.

10. Catalano RC, Hawkins DJ, Berglund ML, Pollard JA, Arthur MW. Prevention science and positive youth development: competitive or cooperative frameworks? J Adolesc Health. 2002;31(6, suppl):230-239.

11. Noonan A. From contrast to concrete: issues in building a skilled and stable out-of-school time workforce. National Institute for Out-of-School-Time; 2001. Available at: http:/ / www.niost.org/publications/cross_cities_brief5.pdf. Accessed September 4, 2005.

12. Camino L, Zeldin S. Making the transition to community youth development: emerging roles and competencies for organizations and youth workers. In: Institute for Just Communities (ed.), Community Youth Development Anthology. Waltham, Mass: Brandeis University; 2002:70-78.

13. Surr WB. Ready to roll: five cities share their experience with recruiting, orienting and first year training of after-school staff. After School Issues, March 2001. National Institute on Out-of-School-Time, Center for Research on Women, Wellesley College, Mass.

14. Wyn J, Harris A. Youth research in Australia and New Zealand. Young J Youth Res. 2004;12(3):271-289.

15. Youth Health, Specialist Certificate in Health Promotion-Youth Work. Galway, Ireland; 2005. Available at: http://www. youthhealth.ie. Accessed September 12, 2006.

16. Partnership for After School Education (PASE) Website. Available at: http:/ /www.pasesetter.com/. Accessed September 4, 2005. 
17. Riser MH, Mesler K, Tallon TC, Birkhead GS. New York State's "Assets Coming Together (ACT) for Youth": A Statewide Approach Effects Community Change. J Public Health Manag Pract. 2006; (suppl):S41-S47.

18. Peake K, Epstein I. Theoretical and practical imperatives for reflective social work organizations in health and mental health: the place of practice-based research. Soc Work Ment Health. 2005;3(1/2):23-37.

19. Schon D. The Reflective Practitioner: How Professionals Think in Action. New York, NY: Basic Books; 1983.

20. Blumenfield S, Epstein I. Promoting and maintaining a reflective professional staff in a hospital-based social work department. Soc Work Health Care. 2001;33(3/4):1-13.

21. Fook J, ed. The Reflective Researcher: Social Workers' Theories of Practice Research. New York: Allen and Unwin; 1996.

22. DeRoos YS. The development of practice wisdom through human problem solving processes. Soc Serv Rev. 1990;64:276287.

23. Goldstein H. Field education for reflective practice: a reconstructive proposal. J Teach Soc Work. 1993;8(1/2):165-182.

24. Bernstein S, Epstein I. Grounded theory meets the reflective practitioner: integrating qualitative and quantitative meth- ods in administrative practice. In: Sherman E, Reid W, eds. Qualitative Research in Social Work. New York: Columbia University Press; 1994:423-434.

25. Epstein I. Promoting reflective social work practice: research strategies and consulting principles. Mullen EJ, Magnabosco JL, eds. Practitioner-Researcher Partnerships: Building Knowledge From, in and for Practice. Washington, DC: NASW Press; 2001;83-102.

26. United Way of America. Measuring Program Outcomes: A Practical Approach. Alexandria, Va: United Way of America; 1996.

27. Guterman NB, Cameron M. Young clients' exposure to community violence: how much do their therapists know? Am J Orthopsychiatry. 1999;69(3):382-391.

28. Schoen C, Davis K, Scott Collins K, Greenberg L, Des Roches C, Abrams M. The Commonwealth Fund Survey of the Health of Adolescent Girls. New York: The Commonwealth Fund; 1997. Available at: http://www.cmwf.org/publications/ publications_show.htm?doc_id=221230. Accessed August 18, 2005.

29. Klein J, Wilson K. Delivering quality care: adolescents' discussion of health risks with their providers. J Adolesc Health. 2002;30:190-195. 